July 2009

\title{
Tactile Hallucinations: Presenting Symptom of Schizophrenia
}

Virgen M. Quinones

Ponce School of Medicine,vm22@hotmail.com

Follow this and additional works at: https://jdc.jefferson.edu/jeffjpsychiatry

Part of the Psychiatry Commons

Let us know how access to this document benefits you

\section{Recommended Citation}

Quinones, Virgen M. (2009) "Tactile Hallucinations: Presenting Symptom of Schizophrenia," Jefferson Journal of Psychiatry. Vol. 22 : Iss. 1 , Article 1.

DOI: https://doi.org/10.29046/JJP.022.1.001

Available at: https://jdc.jefferson.edu/jeffjpsychiatry/vol22/iss1/1

This Article is brought to you for free and open access by the Jefferson Digital Commons. The Jefferson Digital Commons is a service of Thomas Jefferson University's Center for Teaching and Learning (CTL). The Commons is a showcase for Jefferson books and journals, peer-reviewed scholarly publications, unique historical collections from the University archives, and teaching tools. The Jefferson Digital Commons allows researchers and interested readers anywhere in the world to learn about and keep up to date with Jefferson scholarship. This article has been accepted for inclusion in Jefferson Journal of Psychiatry by an authorized administrator of the Jefferson Digital Commons. For more information, please contact: JeffersonDigitalCommons@jefferson.edu. 


\title{
Tactile Hallucinations: Presenting Symptom of Schizophrenia
}

\author{
Virgen M. Quinones-Fernandini ${ }^{1 *}$, Pedro A. Castaing-Lespier ${ }^{1 *}$, Luis Franco ${ }^{1 \xi}$ \\ ${ }^{1}$ Ponce School of Medicine/VA Caribbean Healthcare System Psychiatry Residency Program, \\ Mayaguez Site at "Centro de Salud Conductual del Oeste" Postal Address: \\ P.O. Box 7004 Ponce, PR 00732-7004 ; Physical Address: 388 Zona Ind Reparada 2 \\ Ponce, PR 00716-2347 \\ * These authors contributed equally to this work \\ $\xi$ Case Report Presentation Supervisor \\ Email addresses: \\ VMQF: vm22@hotmail.com \\ PACL: pa castaing@yahoo.com \\ LF: Ifranco@psm.edu
}




\section{Tactile Hallucinations: Presenting Symptom of Schizophrenia}

Virgen M. Quinones-Fernandini, Pedro A. Castaing-Lespier, Luis Franco

\section{Abstract}

Although previous reports about tactile hallucinations of sexual content suggesting Schizophrenia are known ${ }^{2}$, this disorder has been characterized mostly by hallucinations of visual/auditory content. At Schizophrenia presentation these two types of hallucinations are the prominent features. This report describes a patient who had no previous psychiatric symptoms and for whom tactile hallucinations were the presenting symptom of Schizophrenia.

\section{Introduction}

The importance of Schizophrenia relies in the fact that its prevalence is $1 \%$ of the population and is the $4^{\text {th }}$ leading cause of disability among adults. It is an usually chronic disorder, one of the most devastating medical illnesses ${ }^{1}$.

The prodromal phase is defined retrospectively, after the person meets full criteria for the disorder ${ }^{3}$. The prodrome can be described in 2 ways: (1) the earliest, pre-psychotic form of a psychotic disorder (attenuated psychosis), or (2) as a syndrome that confers vulnerability to psychosis development, though psychosis development is not inevitable ${ }^{3}$.

Tactile hallucinations, also called haptic hallucinations, have been described as "sensations of being touched"2 and as "false perception of touch or surface perception" $" 7$. Through history and literature, tactile hallucinations have been associated with drugs/alcohol use/withdrawal, Parkinson's Disease ${ }^{6}$ and with acute brain changes.

Literature review is significant for almost no documentation regarding tactile hallucinations. No reports were found of these hallucinations as a presenting symptom of incipient Schizophrenia. (utilizing what method fro the search) 
Peled A, Ritsner M, et al, in "Touch feel illusion in schizophrenic patients" concluded that in Schizophrenia, altered functional integration of environmental inputs could constitute the basis for erroneous interpretation of reality ${ }^{4}$. Shergill SS, Cameron LA, et al, using fMRI identified somatosensory and post-parietal cortex areas that normally mediate perception as being activated during somatic hallucinations.

This report describes a case of a patient who eventually developed Schizophrenia and presented with tactile hallucinations as the first symptom. According to the National Institute of Mental Health (NIMH), about $75 \%$ of patients diagnosed with Schizophrenia experience hallucinations, most commonly auditory or visual ${ }^{8}$. $80 \%$ of patients diagnosed with Temporal lobe epilepsy (TLE) experience gustatory and olfactory hallucinations as well as auditory and visual hallucinations ${ }^{8}$. Tactile hallucinations have been reported by survivors of rape and childhood sexual abuse ${ }^{8,9}$. Child abuse was a significant predictor of auditory and tactile hallucinations even in absence of adult abuse . $^{9}$

\section{Case Report}

Miss. MS was a 21-year old single woman who was admitted to the inpatient psychiatric unit around December 2004 secondary to 4 months of experiencing tactile hallucinations, 3 months of auditory hallucinations and self-aggressive behavior.

Miss. MS related that in August 2004 she participated in a Botanical Class camp at a mountain in Puerto Rico. During the first week of the camp and while taking classes with classmates, she felt that her face was being touched very lightly by someone she was not able to see or hear. To this caress, Miss. MS responded by pushing away whoever she thought was touching her and told no one about it. This episode continued every day during the fist week of camp.

The night before the recess from camp, Miss. MS was unable to sleep because she felt that someone was touching her legs and arms. She describes that although she had her face covered with her sleeping bag, she saw a silhouette that appeared to have spikes on the head. She thought it was a classmate from camp named CC standing in front of her. This person had dreadlocks on his hair.

Miss. MS reports that she felt her blanket wet and accused her classmate of been masturbating in front of her and touching her. All the classmates of Miss. MS were sleeping in the same room and denied the accusations made by her. One of the professors in charge accused her of being totally insane. Miss MS states that she hid the blanket as evidence, but felt confused when she could not find the stain on it. Miss. MS decided to stay in the camp in 
order to be able to pass the class. That day, the class professor took her to her house for the recess.

While at her house during that night, she felt someone over her body. She describes that she was alone in her room, awake, crying and yelling. She needed to be comforted by her mother so she could be able to sleep. The next day her mother took her to the mountain to finish the camp. She was placed in a different cabin with a female classmate. There, she kept feeling being touched every night but her classmate stated that there was no one in there. Miss. MS claimed that she was able to finish camp thanks to this classmate support.

When Miss. MS arrived home on August 15, 2004, she was unable to sleep and needed to be accompanied by her mother. She started feeling being sexually penetrated and sexually assaulted by someone she could not see. She also felt been spied by her classmate CC. Pt continued having these hallucinations on a daily basis for one month. Her family took her to the patient's uncle who was a priest since her mother thought she was "transformed". The priest advised the family to take Miss. MS to a physician.

After a month, Miss. MS reported feeling dirty and like a "ramera" (whore). She felt that she was constantly raped by multiple men. Then, she started hearing a voice that called her "amor" (love). Auditory hallucinations increased in frequency and complexity. She then heard a man that at first talked to her and then talked to a woman. After one month, Miss. MS heard 12 voices talking between them at the same time. She heard the voices accusing her of making witchcraft and cults when her mother brought her a catholic present to protect her.

Pt reports that at that time she started to remember things from her childhood. She saw herself crying as a child. Then she took her dolls out and started playing with them. She also remembered that her mother and aunt were overprotective with her and that she was always playing by herself.

During the following two months, the patient was taken by her brother to a protestant church near her town. She started to read the bible, especially Apocalypse. She reports that at that moment she realized that she was the woman of "the prophecy" and that the one that raped her was the dragon. Miss. MS relates how she was tormented by this. She lost her faith and felt that she was loosing control of herself. As a result, she started hitting the walls with her head and turned uncontrollable for which she was hospitalized.

Previous to this episode, Miss. MS is able to identify a period of 4 years of increased isolation. During this period she only talked to her brother. She wrote 11 dark-dead poems and gave them to her brother for him to write music for them and play them on his band. Dark poetry wrote by Miss. MS 
was in English language even when her first language is Spanish and she is not that fluent in English. Some poems phrases were: "The dead is calling to my heart..." "The black horse is whining a sound, that nobody knows why... takes you to the valley of the dead". Her mother found the poems when she was hospitalized and threw them away. Miss. MS reports that she used to enter in her brother's computer without permission and saw at times porn sites during that time. Patient related how she felt lonely, sad and inadequate for everything.

After hospitalization, Miss. MS had a neurological evaluation that included: an EEG and a brain CT scan, with negative results. She was treated with Lexapro $10 \mathrm{mg}$ am, Zyprexa $5 \mathrm{mg}$ hs and Benadryl $50 \mathrm{mg}$ hs for the last year but only with partial response: she kept hearing voices on an off on a daily basis but she states were more tolerable than initially. Zyprexa was increased to $10 \mathrm{mg}$ but only with partial response and was eventually discontinued due to $60 \#$ weight gain in 5 months. Lexapro was discontinued also due to patient feeling more depressed at optimal dose. Zoloft was started at $50 \mathrm{mg}$ on am with good response. She was also started on Abilify $7.5 \mathrm{mg}$ am for one week and then the dose was increased to $15 \mathrm{mg}$ am. The patient is stable now with no residual psychosis for the last 3 months while on Abilify.

At this moment, Miss. MS thinks that what she lived was totally real, she thinks that it was a bad spirit that disappeared only with her faith and the medications. Miss. MS exhibits excellent compliance with medications. She was able to complete her BA in Biology with honors even while hearing voices talking about her and criticizing her. In retrospect, she resents the feeling that her personality has changed. She does not want to socialize and has no desire to talk to anyone about anything; but feels well about the disappearance of her hallucinations.

\section{Discussion}

Miss. MS has required only one hospitalization since the beginning of her illness, this may be due to her compliance with medical treatment. Complete neurological workup revealed no organic cause for her symptomatology. Miss. MS denied any illicit drug/alcohol use. As per family reports, there is no family history of Schizophrenia.

Miss. MS was born with an eye spasm which still makes her unable to close the right eye even when asleep. On physical examination it is appreciated face asymmetry as well as deformity of her fingers. An ovarian cyst was diagnosed after menarche due to severe blood loss during a year period. During an appendectomy and ovarian cyst removal, she was incidentally 
found to have an abdominal kidney. Upon literature review no correlation was found between this presentation and Schizophrenia development. Literature describes several syndromes of genetic origin with severe consequences in organ functioning that are associated with disorganization, psychosis and aggressive behavior. Miss. MS do not fit any of the syndromes presentation, however we cannot discard the possibility of a correlation between this physical findings and her illness development. Reports of many associations between chromosomal sites and Schizophrenia are known ${ }^{7}$, more than half of all chromosomes have been associated with Schizophrenia but the most commonly implicated are the long arms of chromosomes 5, 11 and 18, the short arm of chromosome 19 and the X chromosome.

Miss. MS reported feeling sad and lonely as a child, she denied physical or sexual abuse. Miss. MS related how she only had one or two friends, and was never too close to them. This behavior is typical of the premorbid history of Schizophrenia7. Pre-schizophrenics adolescents as Miss. MS, have no close friends, no dates and avoid team sports. They enjoy things that led to the exclusion of social activities as watching television or using the computer.

Miss. MS prodormal phase lasted about 4 years. Common prodromal signs include anxiety, blunted affect, social isolation, irritability, depression or dysphoric mood. In this patient criteria for a major depressive episode was not met but she presented with dysphoric mood and social isolation. Her feeling of being lightly touched during the week previous to the tactile hallucinations development can be identified as an attenuation of the psychosis.

During the year of 2005, the patient was treated with several medications by her neurologist which was the person that initiated her treatment. These included Depakote, Geodon, Seroquel, Risperdal, Zyprexa and Abilify, in unkown doses an apparently with a very poor response from patient. In terms of treatment, this patient had the recommended course which included exclusion of medical causes and immediate treatment of psychosis even in absence of the Schizophrenia diagnosis. Of the medications used, only Abilify has no reports published (up to 2005) as treatment for first episode Schizophrenia ${ }^{1}$. In this case, the patient had an excellent response upon dosage optimization and has been able to be maintained in remission of psychotic symptomatology.

\section{Conclusion}

This case is very interesting because of the Schizophrenia presentation. Her initial presentation made it difficult to diagnose since several factors needed to be clarified. Sexual molestation needed to be explored to rule out the possibility of a PTSD. 
As time passed, the patient developed symptoms characteristics of Schizophrenia that included: paranoid delusions, disorganized thoughts, disorganized behavior and tactile/auditory hallucinations for more than 6 months. In retrospect the prodromal period was clearly identified. Miss. MS did not present with symptoms that fulfill the criteria for a major depressive episode or manic episode during her illness development. She presented with sad mood after she gained some insight about her condition.

This report is significant for the occurrence of tactile hallucinations as the presenting symptom of incipient Schizophrenia. It also reminds us of being aware of the prodromal symptoms of Schizophrenia and raises the question of the possibility of prophylactic treatment for schizophrenic patients.

\section{Competing Interests}

The authors declare that they have no competing interests.

\section{Authors' Contributions}

VMQF was the person that interviewed the patient and was constantly in contact with her, organized the case presentation and manuscript. PACL was the in-site attending who supervised each visit and with whom treatment decisions were consulted, he was also the psychiatrist who suggested the search for medical correlations and previous workup done to patient plus the collateral history gathering. PACL was also the main editor of the case report. LF was the case presentation supervisor, he is also the department chairman that provided general support and was the person who suggested more history clarification and detailed description of tactile hallucinations to sustain the diagnosis.

\section{Acknowledgements}

The authors gratefully acknowledge the cooperation of the patient described in this case report, from whom verbal consent was obtained for the publication of this study. VMQF would like to thank PACL for his help in the literature review for the case and for his constant support and availability as an attending psychiatrist. 


\section{References}

1. Kelly DL, Conley RR and Carpenter WT: First-Episode Schizophrenia. A Focus on Pharmacological Treatment and Safety Considerations. Drugs. 2005; 65(8)1113-1138.

2. McMorran J, Crowther DC, McMorran S, Prince C, YoungMin S, Pleat J, Wacogne I: General Practice Notebook. Oxbridge Solutions Ltd® 2004. Tactile Hallucinations. 1-15.

3. Comptom MT, et. al.: Advances in Early Intervention in the Prodromal Phase of Schizophrenia CME/CE. American Psychiatric Association 2005 Annual Meeting/Schizophrenia; 1-4.

4. Peled A, Ritsner M, Hirschmann S, Geva AB, Modai I: Touch feel Illusion in schizophrenic patients. Biol Psychiatry. 2000 Dec 1; 48(11): 1105-8.

5. Shergill SS, Cameron LA, Brammer BJ, Williams SC, Murray RM, McGuire PK: Modality specific neural correlates of auditory and somatic hallucinations. J Neurol Neurosurg Psychiatry. 2001 Nov; 71(5)688-90.

6. Fenelon G, Thobois S, Bonnet AM, Broussolle E, Tison F:Tactile hallucinations in Parkinson's disease. J Neurol. 2002 Dec; 249(12)1699-703.

7. Sadock BJ, Sadock VA: Synopsis of Psychiatry. Behavioral Sciences/Clinical Psychiatry. In Schizophrenia. $9^{\text {th }}$ Edition. Edited by Cancro R, et. al. Philadelphia, PA: Lippincott Williams \& Wilkins; 2003:285,471-504.

8. Demographics [http://www.healthline.com/galecontent/hallucination]

9. Read J, Agar K, Argyle N, Aderhold V: Sexual and physical abuse during childhood and adulthood as predictors of hallucinations, delusions and thought disorder. Psycholo Psychother. 2003 Mar;76(Pt 1) $1-22$.

10. Kobayashi T, Kato S: Psychopatology and outcome of first-admission schizophrenic patients: Hypocondriac-cenestophatic symptoms as predictors of an unfavorable outcome. Psychiatry and Clinical Neurosciences 2004(58)567-72. 
11. Townsend LA, Norman RM: Course of cognitive functioning in first episode schizophrenia spectrum disorders. Expert Rev Neurother. 2004 Jan;4(1)61-8.

12. Lindenmayer JP, Khan A: Pharmacological treatment strategies for schizophrenia. Expert Rev Neurother. 2004 Jul;4(4)705-23.

13. Chen EY, Hui CL, Chan RC, Dunn EL, Miao MY, Yeung WS, Wong CK, Chan WF, Tang WN: A 3-year prospective study of neurological soft signs in first-episode schizophrenia. Schizophr Res. 2005 Jun $1 ; 75(1) 45-54$.

14. Norman RM, Scholten DJ, Malla AK, Ballageer T: Early signs in schizophrenia spectrum disorders. J Nerv Ment Dis. 2005 Jan;193(1)17-23.

15. Harris A, Brennan J, Anderson J, Taylor A, Sanbrook M, Fitzgerald D, Lucas S, Redoblado-Hodge A, Gomes L, Gordon E: Clinical profiles, scope and general findings of the Western Sydney First Episode Psychosis Project. Aust N Z J Psychiatry. 2005 Jan-Feb;39(1-2)36-43.

16. Shelvin M, Dorahy M, Adamson G: Chldhood traumas and hallucinations: An analysis of the National Comorbidity Survey. J Psychiatr Res. 2007 Apr-Jun;41(3-4)222-8. Epub 2006 Apr 27.

17. Proctor SE, Mitford E, Paxton R: First episode psychosis: a novel methodology reveals higher than expected incidence; a reality-based population profile in Northumberland, UK. J Eval Clin Pract. 2004 Nov; $10(4) 539-47$.

18. Benke T: Peduncular hallucinosis: A syndrome of impaired reality monitoring. J Neurol. 2006 Sep 27; [Epub ahead of print].

19. Pao M, Lohman C, Gracey D, Greenberg L: Visual, tactile and phobic hallucinations: recognition and management in the emergency department. Pediatr Emerg Care. 2004 Jan;20(1)30-4.

20. Haroun N, Dunn L, Haroun A, Cadenhead KS: Risk and protection in prodromal schizophrenia: Ethical implications for clinical practice and future research. Schizophrenia Bulletin 2005 Oct 5;32(1)166-78,2006.

21. Gosden R: Pre-Psychotic Treatment for Schizophrenia: Preventive Medicine, Social Control, or Drug Marketing Strategy? Ethical Human Sciences and Services 1999;1(2)165-177. 